\title{
Experimental and finite element analyses of multifunctional skins for morphing wing applications
}

\author{
Sebastian Geier , Markus Kintscher, Thorsten Mahrholz, Peter Wierach, Hans-Peter Monner, \\ Martin Wiedemann; \\ Institute of Composite Structures and Adaptive Systems, \\ DLR e.V. (German Aerospace Center), \\ Lilienthalplatz 7, Braunschweig, Germany
}

\begin{abstract}
As a consequence of operational efficiency because of rising energy costs, future transport systems need to be mission-adaptive. Especially in aircraft design the limits of lightweight construction, reduced aerodynamic drag and optimized propulsion are pushed further and further. The first two aspects can be addressed by using a morphing leading edge. Great economic advantages can be expected as a result of gapless surfaces which feature longer areas of laminar flow. Instead of focusing on the kinematics, which are already published in a great number of varieties, this paper emphasizes as major challenge, the qualification of a multi-material layup which meets the compromise of needed stiffness, flexibility and essential functions to match the flight worthiness requirements, such as erosion shielding, impact safety, lighting protection and de-icing. It is the aim to develop an gapless leading edge device and to prepare the path for higher technology readiness levels resulting in an airborne application. During several national and European projects the DLR developed a gapless smart droop nose concept, which functionality was successfully demonstrated using a two-dimensional $5 \mathrm{~m}$ in span prototype in low speed (up to $50 \mathrm{~m} / \mathrm{s}$ ) wind tunnel tests. The basic structure is made of commercially available and certified glass-fiber reinforced plastics (GFRP, Hexcel Hexply 913). This paper presents 4-point bending tests to characterize the composite with its integrated functions. The integrity and aging/fatigue issues of different material combinations are analyzed by experiments. It can be demonstrated that only by adding functional layers the mentioned requirements such as erosion-shielding or de-icing can be satisfied. The total thickness of the composite skin increases by more than $100 \%$ when required functions are integrated as additional layers. This fact has a tremendous impact on the maximum strain of the outer surface if it features a complete monolithic build-up. Based on experimental results a numerical model can be set up for further structural optimizaton of the multi-functional laminate.
\end{abstract}

Keywords: smart droop-nose, morphing structure, morphing wing, morphing leading-edge, laminar natural flow, laminar wing concept, electrical heating, de-icing

\section{INTRODUCTION}

Energy efficiency is the most driving motivation for research in aviation to keep competitive to other form of transport. Among other disciplines aerodynamics and lightweight design are the main drivers for optimization of modern aircrafts. E. g. the reduction of the aerodynamic drag during cruise has decisive impact on the total energy consumption therefore it features in the clean-configuration almost no lift. In contrast during the start, climb, decent and landing phase the wing of an aircraft must generate lift. Its shape has to change by raising its camber using modern high-lift devices like slats at the leading and fowler flaps at the trailing edge of an aircraft's wing. A great disadvantage of the used systems are gaps and edges between the wing body and the attached slats and flaps which are responsible for the transition of the laminar to the turbulent, drag intensive flow. Future wing concepts have to improve their aerodynamic efficiency by long or complete laminar flow around the wing. This paper focuses on leading-edge devices which are morphing and gapless using flexible materials. Since the beginning of man powered flight various publications deal with kinematics ${ }^{1-3}$ to morph the

Further Author Information: Send Correspondence to Sebastian Geier E-mail: Sebastian.Geier@dlr.de, Telephone: +49 5312952355

Sensors and Smart Structures Technologies for Civil, Mechanical, and Aerospace Systems 2016,

edited by Jerome P. Lynch, Proc. of SPIE Vol. 9803, 980328 - (c) 2016 SPIE

CCC code: $0277-786 \mathrm{X} / 16 / \$ 18 \cdot$ doi: $10.1117 / 12.2219357$

Proc. of SPIE Vol. $9803980328-1$ 
leading-edge or even the whole airfoil. Up to now there is a great variety of reviews ${ }^{4-8}$ published. However, comparatively short chapters are addressing the material selection although this topic is the most challenging one. The latest publications also deal with topology optimization of compliant wing structures. ${ }^{9}$ The inner structure is designed as an array of solid joints which can only be realized by using a flexible and stiff material. This paper focuses on characterization and modelling of skin materials. Typically elastomeric skins are used to demonstrate the mechanism. The compliant wing concepts of Kota and Hetrick ${ }^{10}$ were the first applicable approaches to investigate a suitable, flexible skin material. They used combinations of aluminum and polymer on the upper surface and the same hybrid with added reinforced elastomeric panels on the lower surface to meet flight requirements for a real in-flight demonstration. Other approaches based on glass or carbon fiber reinforced elastomeric matrices ${ }^{11,12}$ which are suitable materials for remote controlled aircrafts but would failure to transfer aerodynamic loads of commercial wide-body aircrafts. A step towards this application can be seen in composites which are arranged in flexible, corrugated structures with a sinusoidal ${ }^{13}$ or omega-like ${ }^{3}$ shape. However, these segmented skin concepts were difficult to manufacture, react sensibly on manufacturing imperfections and finally feature no smooth surface. Another approach of Thill ${ }^{4}$ were elastomer-coated sandwiches of different types also including auxetic materials. An alternative way was described by Kirn ${ }^{14}$ developing a flexible matrix composite. Here woven carbon- or glass-fibers are infiltrated by silicone or thermoplastic elastomers to gain a flexible and stiff composite material. Kirn's approach focused on the design for flexible, cellular tube-like actuators but it was also used for flexible skins of morphing devices ${ }^{15}$ and unfolded space deflectors. ${ }^{16}$ The patent of a leading-edge with closed, flexible panels and an internal kinematic for tilting the whole leading-edge was developed by the Dornier company ${ }^{17}$ in the late seventies (shown in Figure 1 a)) and points out the idea behind the presented DLR-morphing device.

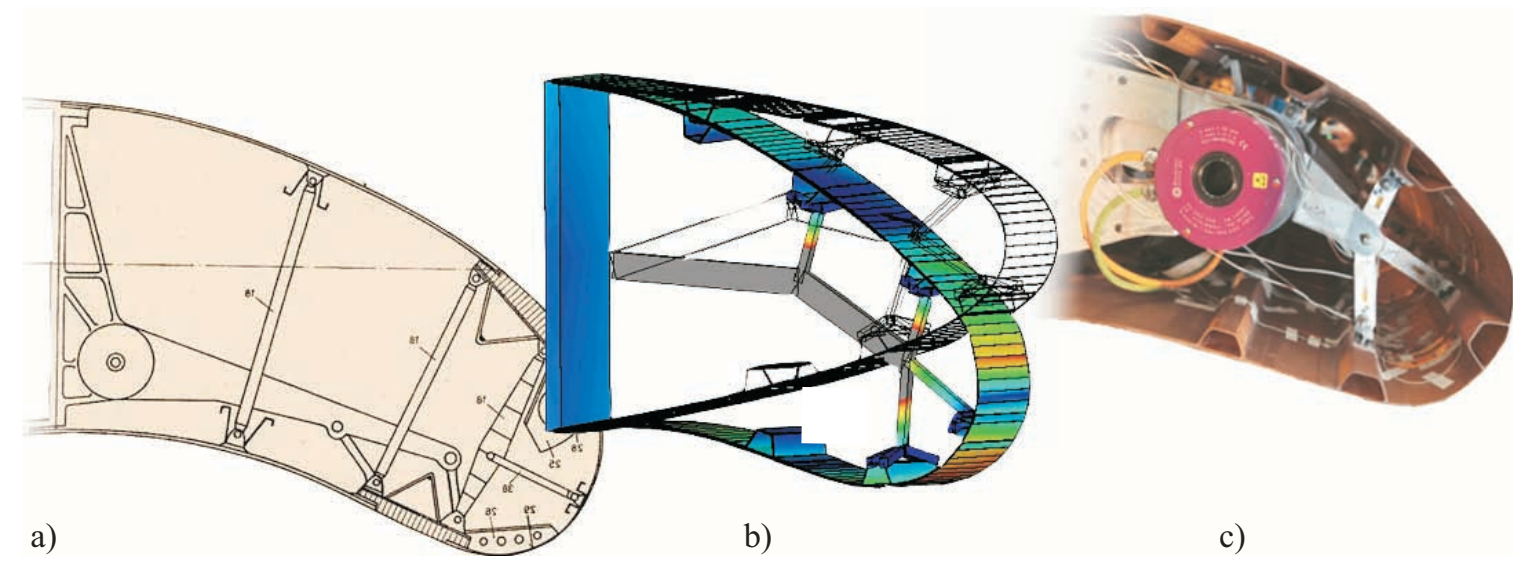

Figure 1. Evolution of the DLR morphing leading-edge concept:

a) Drawing of the Dornier patent ${ }^{17}$.

b) 3-dimensional FE-shape of leading edge featuring a variable thickness ranging from 1 to $5 \mathrm{~mm}$.

c) Realized structure for the first full-scale ground tests.

At the German Aerospace Center (DLR) the Dornier concept was advanced, what means simulated designed and realized, for composites (see Figure $1 \mathrm{~b}$ )). Its flexibility is achieved by a variable thickness distribution ${ }^{18}$ which allows an inboard kinematic to lower the leading-edge to an angle of attack of $20^{\circ}$. The material of the skin is only stressed in bending manner so that is not stretched plastically along the bending line. So, the aim is to keep the wall thickness as small as possible. As basic material monolithic glass fiber reinforced polymer (GFRP, Hexply 913, Hexcel Corporation) is used. It can bear comparative high strain up to 3.3 to $4.2 \%^{19}$ and feature acceptable Young's modulus ranging between 55000 and $86610 \mathrm{MPa}^{20}$ (regarding the mechanical properties of pure glass fibers) to stand the aerodynamic loads. Heintze ${ }^{21}$ reported about the experimental background of material qualification and optimization for the full-scale ground test of a 3-dimensional segment of two meter span (also see Figure $1 \mathrm{c}$ )) which was intended as feasibility study. For verification of the shape accuracy under relevant aerodynamic loading a wind tunnel test was successfully conducted 2013 with a full-scale 2-dimensional wind tunnel model of $5 \mathrm{~m}$ span and $3 \mathrm{~m}$ chord length ${ }^{18}$ (see Figure 2 a)) and again 2015 as 3-dimensional 3 
m span segment of a completely equipped adaptive wing model (see Figure 2 b)). The shown outboard wing segment is the result of the technology stream morphing which is part of the European funded project SARISTU. The droop nose was developed within the work package AS01 and combined with other technologies such as a morphing trailing edge, flexible section between wing and winglet and a morphing winglet within the integration stream IS12. The whole wing was tested in the t104 wind tunnel of the Russian Central Aerohydrodynamic Institute (TsAGI). In the tests the structural deformation under various angles of attack and flow speed up to $120 \mathrm{~m} / \mathrm{s}$ was measured. Furthermore the aerodynamic drag was analyzed in order to reveal the advantages of the gapless design. However, it was found that manufacturing related tolerances have a large impact on the sensitive flow at the leading-edge upper side of the profile.

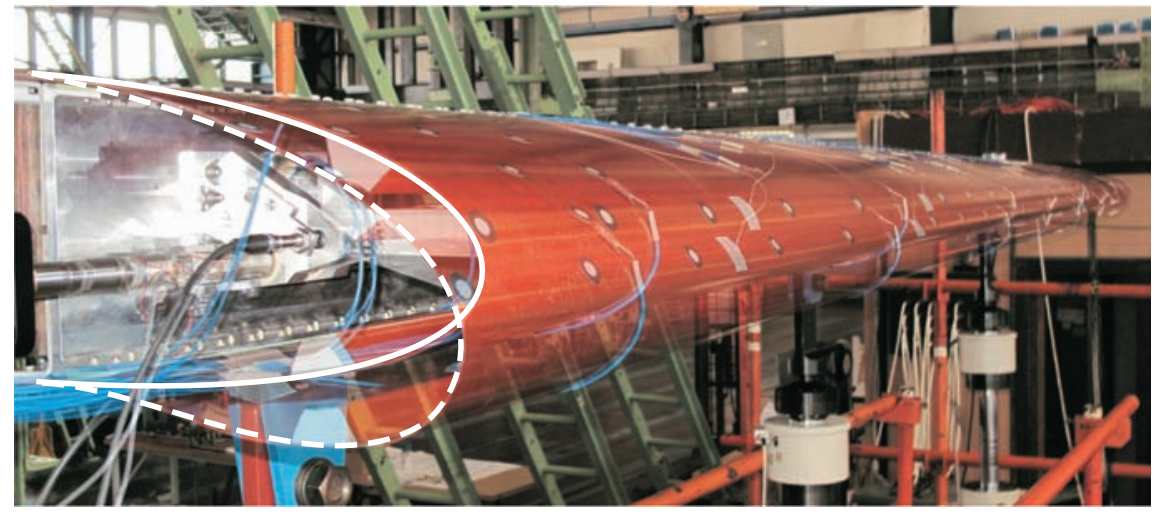

a)

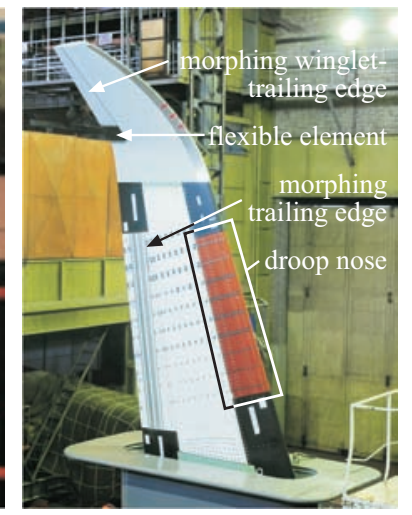

b)

Figure 2. Full-scale testing of the DLR morphing leading-edge:

a) $4 \mathrm{~m}$ span ground test 2015. The clean (white line) and drooped (dashed white line) configurations are shown.

b) Full-scale test of a outboard section of a morphing wing at the t101 wind tunnel of TsAGI with the $3 \mathrm{~m}$ span morphing leading edge (box) and other adaptive, integrated systems.

This paper focuses on mechanical testing and simulated results simultaneously. The experimental results are underlined by finite element (FE) simulations of fundamental laminate stacking configurations for the interpretation of the material behavior of multi-material layups. The focus is on the mechanical effects of the combination of materials with large variation in stiffness like GFRP, steel foil and elastomers.

\section{EXPERIMENTAL}

The experimental chapter is divided into three parts starting with the specimen preparation. The next chapter presents the mechanical testing and test series. The third chapter gives details of the numerical simulations and analytical calculations. The final chapter presents all used formulae.

\subsection{Specimen preparation}

For a successful application of a morphing skin it needs to fulfill various airworthiness requirements e.g. impact protection, abrasion-shielding, lightning protection and the capability for de-icing. Therefore it is not only a challenge to find and characterize a material which combines flexibility and stiffness, also a multi-functional skin has to be developed. In literature several stand-alone solutions for individual tasks such as the integration of an abrasion shielding by using a steel film ${ }^{22}$ or integrated de-icing systems ${ }^{23,24}$ using electro-thermal devices are presented. However, there is no literature about the combination of these techniques and their integration into a flexible leading edge system. The understanding of the impact on the materials and its numerical simulation is the focus of this paper.

For getting this material multifunctional the DLR favored the manufacturing of a hybrid composite. Considering a linear increasing maximum strain over the skin thickness the aim is to double use materials in order to reduce the skin thickness. Ideally one material with a moderate thickness can feature all necessary functions instead 
of adding a new material with an individual thickness for every function. That is the reason for the presented approach of integrating an elastomeric layer, which acts like an impact shield, can electrically insulate the electrified inner structure and can include the de-icing system. Moreover, it is compatible to the used glass-fiber based prepreg. In earlier publications the energy absorption, ${ }^{25}$ a sufficient interface-adhesion to metal layers ${ }^{26}$ and between EPDM and GFRP ${ }^{21}$ could already be demonstrated successfully.

The layup of the skin starting from the outer side is as follows. A $0.05 \mathrm{~mm}$ thick metal film is used as erosionshield (X10CrNi18-8, Stahl Becker GmbH). This erosion layer has to be prepared by a metal primer (Delo Saco Plus, Delo Industrie Klebstoffe GmbH \& Co KGaA) and an adhesive film (3M DP490, 3M Deutschlad GmbH) for keeping fixed on the composite. As electrical insulation two layers of glass-fiber prepreg (Hexply 913 GFRPprepreg, Hexcel Corporation) with an individual thickness of $0.125 \mathrm{~mm}$ are forming the next layer. At this position a de-icing layer using the electro-thermal effect is added. Here, two different materials are tested: on the one hand a CNT-coated paper (B-Heat Paper, albnano carbon systems) with a thickness of $0.125 \mathrm{~mm}$ and on the other hand a $0.25 \mathrm{~mm}$ thick carbon fiber mesh is used as resistance heaters. Below the de-icing system a 0.5 $\mathrm{mm}$ thick elastomer film (ethylene-propylene-diene-rubber abbreviated EPDM, AA6CFZ, Gummiwerke Kraiburg $\mathrm{GmbH} \& \mathrm{Co} . \mathrm{KG}$ ) represents the impact-tolerant and thermal insulating layer. The mainly loaded structure is made of eight layers of the already mentioned GFRP-prepreg. The layup features symmetrical orientation of fiber layers: the two outer layers are oriented in $0^{\circ}$-direction because of the higher strain while the internal four layers are alternately $+45^{\circ}$ and $-45^{\circ}$ oriented for transferring the shear and to avoid interlaminar failures as result of a prevented transverse strain as it is the case for $90^{\circ}$ layers. Originally the thickness of the critical segment should not exceed $1 \mathrm{~mm}$ for having no irreversible, pastical strain of the outer most layers. The here presented layup features an theoretical overall thickness between $1.925 \mathrm{~mm}$ and $2.05 \mathrm{~mm}$ referring to the used heating system. Furthermore the thickness can be higher due to the electrical connectors and manufacturing-based imperfections. All specimens are manufactured by hand using a 6 bar pressurized two stage $\left(+80{ }^{\circ} \mathrm{C}\right.$ and $\left.+120{ }^{\circ} \mathrm{C}\right) 6$ hours curing process recommended by Hexcel and optimized by the DLR. The whole composite is consolidated within one process step. In terms of quality assessment the manufactured composite plates are controlled in thickness and cut into the specimen geometry (width of $15 \mathrm{~mm}$ ) required by the test standard. The specimen layup refers to the critical position of the layup at the leading-edge. That is the reason why all tests have to be considered as structural tests instead comparative material tests.

Furthermore the specimens are aged to simulate service conditions. The aging is carried out within a climatic chamber (VC0020, Vötsch Industrietechnik $\mathrm{GmbH}$ ) at $+70{ }^{\circ} \mathrm{C}$ and $85 \%$ relative humiditiy over at least 3 month for sufficient water saturation.

\subsection{4-point bending set-up}

The material orientation and load within the real leading-edge structure is similar to a 4-point bending test (see Figure 3 a)) according to the German standard of the DIN EN ISO 14125. ${ }^{27}$ The omega stringers of the droop-nose structure, six in a row arranged in the circumference of the leading-edge as it can be seen in Figure 1 b) and c), transfer forces via their two flanks respectively into the skin. The 4-point bending test focuses on the maximum strain of the skin and its failure. Although the standard claims a thickness of $2 \mathrm{~mm}$ for GFRP the presented tests are carried out using the mentioned hybrid layup. Thus, the found statements are considered to evaluate the critical structure instead of evaluating material properties. The goal of this test is to analyze and compare the bending behavior in order to find a load tolerating layup and to evaluate the change of mechanical properties by combining materials. The test set-up and specimen dimensions are depicted in Figure 3. The realized set-up with tested specimen is shown in Figure $3 \mathrm{c}$ ).

The configuration of the 4-point test-rig depends on the material class. Thus, GFRP samples with a thickness of $1 \pm 0.1 \mathrm{~mm}$ are tested and considering the standard fixed L/h-ratio of 22.5 a span length $\mathrm{L}$ of $24 \mathrm{~mm}$ is required (Figure $3 \mathrm{~b})$ ). The average span length $\mathrm{L}^{\prime}$ is $\mathrm{L} / 3$ (see Figure $3 \mathrm{c}$ )). For a better comparison of earlier results the test parameters are kept constant for the samples although they have larger thicknesses. The structural material (GFRP-prepreg) still has a thickness of $1 \mathrm{~mm}$ and since in the real structure the stringer geometry will not be adapted according to the skin thickness this structural test will be carried out in the same way. The tests are carried out a tensile testing machines (1484, Zwick GmbH \& Co. KG) with a 5kN load cell (Zwick GmbH \& Co. KG). The deflection sensor is positioned in the middle of the span (W10TK, Hottinger Baldwin Messtechnik $\mathrm{GmbH}$ ). The tests are conducted with a velocity of $3 \mathrm{~mm} / \mathrm{min}$ and a prestress of $3 \mathrm{~N}$. The radii 


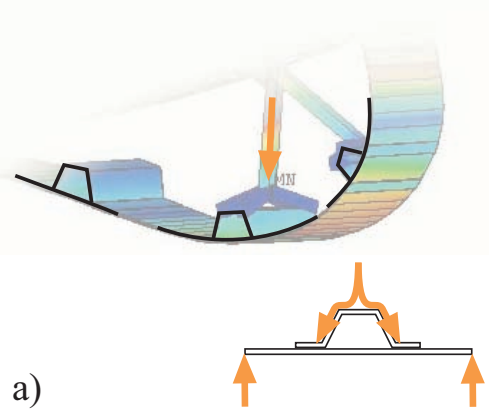

a)

Figure 3. 4-point bending test:
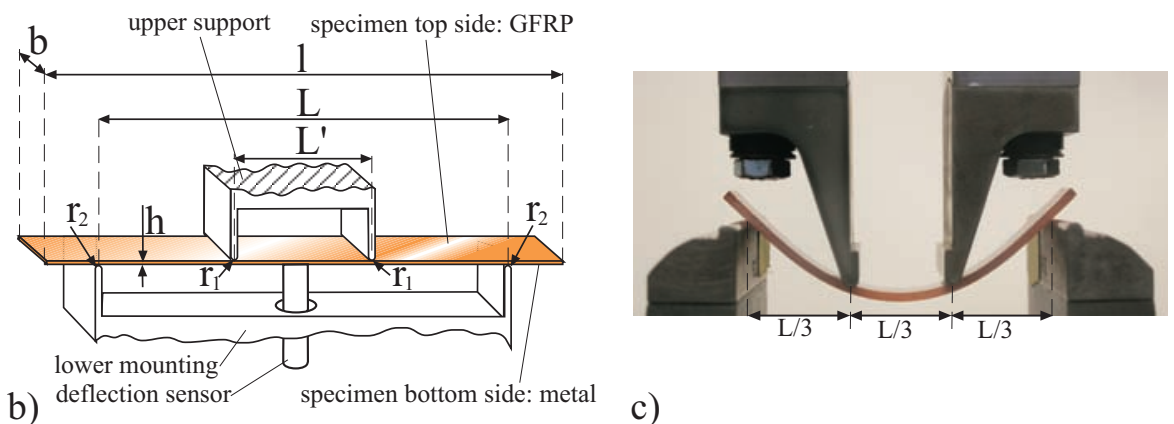

c)

a) Test inspired by the critical part of the structure (see Figure $1 \mathrm{~b}$ )).

b) Schematical sketch of the test-facility.

c) Image of a conducted experiment and allocation of the mounting length $\mathrm{L}$.

of the mountings $r_{2}$ and $r_{1}$ are $2 \mathrm{~mm}$ respectively. The maximum strain of the outer layers of the specimen is measured by one strain gauge respectively, one on the top and one on the bottom of the sample. Because of the small space between the upper mounting on the top of the specimen a array of a 1/120KY21 (Hottinger Baldwin Messtechnik $\mathrm{GmbH}$ ) strain gauge is cut into the individual strain gauges. At the bottom the strain gauges are positioned eccentrically because of the tip of the deflection sensor.

Table 1. Geometry of the bending test set-up according to the specimen sizes.

\begin{tabular}{|c|c|c|c|c|c|c|}
\hline $\begin{array}{c}\text { specimen } \\
\text { type }\end{array}$ & $\begin{array}{c}\text { specimen } \\
\text { length } \\
{[\mathrm{mm}]}\end{array}$ & $\begin{array}{c}\text { specimen } \\
\text { width } \\
{[\mathrm{mm}]}\end{array}$ & $\begin{array}{c}\text { specimen } \\
\text { thickness } \\
{[\mathrm{mm}]}\end{array}$ & $\begin{array}{c}\text { distance } \\
\text { upper mounting } \\
{[\mathrm{mm}]}\end{array}$ & $\begin{array}{c}\text { distance } \\
\text { lower mounting } \\
{[\mathrm{mm}]}\end{array}$ & $\begin{array}{c}\text { mounting } \\
\text { radii } \mathrm{r}_{2}, \mathrm{r}_{1} \\
{\left[{ }^{\circ}\right]}\end{array}$ \\
\hline 1 & 70 & 15 & 2.53 & 8 & 24 & 2 \\
\hline 2 & 70 & 15 & 2.54 & 8 & 24 & 2 \\
\hline 3 & 70 & 15 & 2.84 & 8 & 24 & 2 \\
\hline
\end{tabular}

In contrast specimens manufactured with a heating layer exhibit an increased thickness. For better infiltration of the composite and to avoid a separation as result of a continuous layer of CNT-coated paper it is perforated by holes. As a compromise between homogeneous two-dimensional heating and sufficient interlaminar adhesion two diameters of holes are tested: $4 \mathrm{~mm}$ (test-series 1 ) and $10 \mathrm{~mm}$ (test-series 2).

\subsection{Simulation}

For comparison the 4-point bending test is modelled using composite shell elements SHELL181 of the ANSYS element bibliography. The simulation is performed considering geometric non-linear behavior including contact between the bearing and the specimen and the stamp and the specimen. In Figure

Four configurations are tested in simulations for investigation of the effect of the integrated erosion protection metallic foil and the EPDM elastomeric materials. An overview of sample geometries is given in Table 2. The parameters of the 4-point bending set-up, such as distances of the lower and upper mounting and the used radii are kept constant and can be reprised in Table 1.

\subsection{Mathematical formulae}

The Young's modulus for 4-point bending $\mathrm{E}_{f}$ is calculated by the following formula $(1)^{27}$. The force $\mathrm{F}$ and the deflection $\mathrm{s}$ are the two input parameters measured by the tensile testing machine.

$$
E_{f}=\frac{0,21 \cdot L^{2}}{b \cdot h^{3}} \frac{\Delta F}{\Delta s}
$$




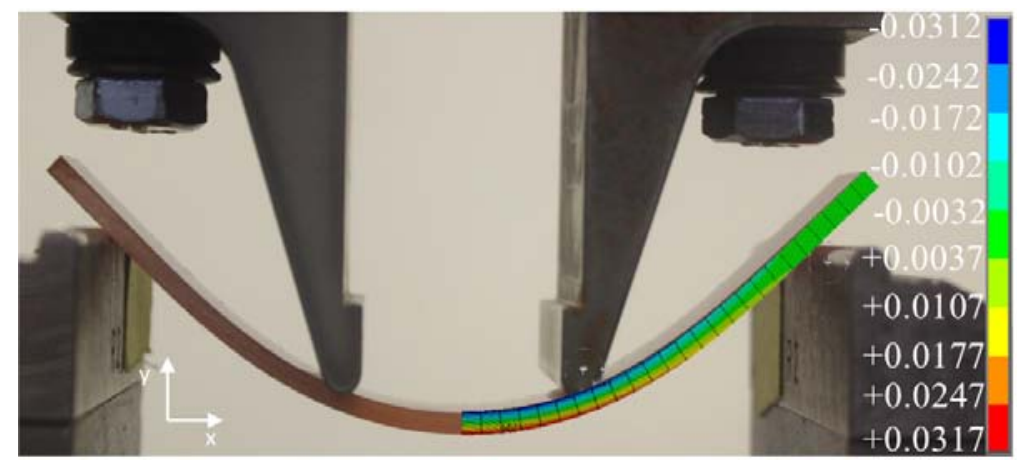

Figure 4. Comparison of experiment (left side) in contrast to the result using finite element analysis (right side) combined in a superimposed image.

Table 2. Geometry and layup of the simulated bending tests.

\begin{tabular}{|c|c|c|c|c|c|}
\hline $\begin{array}{c}\text { specimen } \\
\text { type }\end{array}$ & $\begin{array}{c}\text { specimen } \\
\text { length } \\
{[\mathrm{mm}]}\end{array}$ & $\begin{array}{c}\text { specimen } \\
\text { width } \\
{[\mathrm{mm}]}\end{array}$ & $\begin{array}{c}\text { specimen } \\
\text { thickness } \\
{[\mathrm{mm}]}\end{array}$ & metal film & EPDM film \\
{$[\mathrm{mm}]$} & {$[\mathrm{mm}]$} \\
\hline pure GFRP & 70 & 15 & 2.2 & no & no \\
\hline GFRP+metal & 70 & 15 & 2.2 & 0.2 & no \\
\hline GFRP+EPDM1 & 70 & 15 & 2.2 & no & 0.2 \\
\hline GFRP+EPDM2 & 70 & 15 & 2.5 & no & 0.5 \\
\hline
\end{tabular}

$$
\Delta F=F_{n-1}-F_{n}
$$

$$
\Delta s=s_{n-1}-s_{n}
$$

$E_{f} \quad[\mathrm{~Pa}] \quad$ Young's modulus

$L \quad[\mathrm{~mm}]$ length between the support

$b \quad[\mathrm{~mm}]$ width of sample

$F \quad[\mathrm{~N}] \quad$ measured force

$s \quad[\mathrm{~mm}]$ measured vertical deflection

The Young's modulus is calculated between $10 \%$ and $50 \%$ of the maximum force. The achievable maximum strain $\epsilon_{f}$ is calculated according to the following formula $(4)^{27}$.

$$
\epsilon_{f}=\frac{4,7 \cdot s \cdot h}{L^{2}}
$$

$\epsilon_{f} \quad[\%]$ maximum strain

The strain of the strain gauges are calculated by the acquisition-system (MGC+, Hottinger Baldwin Messtechnik $\mathrm{GmbH})$ using the specific k-parameter.

\section{RESULTS AND DISCUSSION}

Firstly the 4-point bending tests are simulated to demonstrate the effect of an elastomer layer on the strain on the outer surfaces. Considering these results the 4-point bending tests of the de-icing layups are presented with a focus on the maximum strain and mean Young's modulus as result of different layups and material combinations. Finally the layup ist tested within a small droop-nose demonstrator to show the the accordance between the results of the simulations and experiments. 


\subsection{Prelimiary Finite element simulations of the 4-point bending tests}

Compared to the reference configuration of $2.2 \mathrm{~mm}$ pure $0^{\circ}$ GFRP, the application of a $0.2 \mathrm{~mm}$ steel foil on top of the basic $2.0 \mathrm{~mm}$ laminate results in an altered strain distribution as it can be seen in Figure 5. Since the stiffness of the metallic foil is much higher than the underlying GFRP the neutral fiber is shifted, the strain distribution becomes asymmetric (compare red boxes and green triangles). The strain in the metallic foil is with $1.3 \%$ small compared to the outer glass fibers of the reference laminate which are stretched for $2.2 \%$. Taking the maximum strain of the Hexply glass fibers with about $2.1 \%$ into consideration this result is of high importance for material failure.

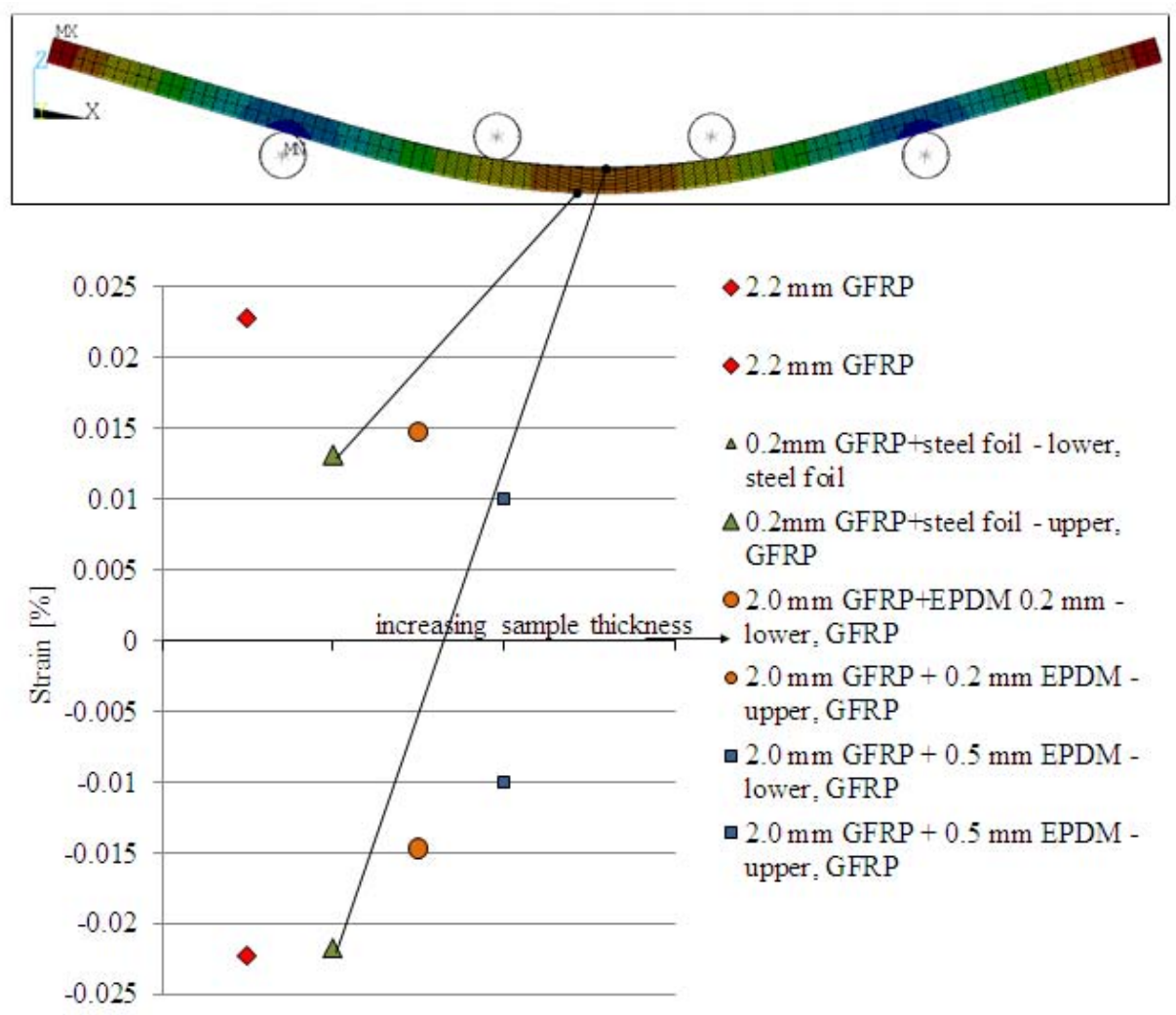

Figure 5. Overview of the maximum strain at the outer surfaces of the four simulated configurations.

The two samples using an elastomer layer of varying thickness point out a theoretical way to reduce significantly the maximum strain at the outer layers (see orange dots and blue boxes). While the reference configuration features a maximum strain of $2.2 \%$ both outer layers, an elastomer layer of $0.2 \mathrm{~mm}$ reduces the strain as result of mechanical decoupling by $50 \%$ down to $1.47 \%$. A larger EPDM-layer with a thickness of $0.5 \mathrm{~mm}$ further reduces the strain to a value of only $0.1 \%$. These results point out that also skins of larger thicknesses can be bended without causing mechanical damage by being deformed plastically if they are mechanically decoupled.

\subsection{Results of 4-point bending tests}

The bending tests are considered to simulate the bending mode during morphing of the leading-edge. It is necessary to check the elasticity of the material combination in terms of meeting the requirements of $1 \%$ material strain which is necessary to reach the drooped position. These tests are carried out until failure of the specimen to analyze the failure mechanism and the maximum reachable strain. The tests are conducted at room temperature and the results are presented in Table 3 and in Figure 6.

The results of the Young's modulus, maxium force and maximum strain reveal a clear aging effect of all devices. As mentioned in section 2.1 the aging was conducted for three months at at $+70{ }^{\circ} \mathrm{C}$ and $85 \%$ relative 
Table 3. Overview of the mechanical results measured during the 4-point bending test.

\begin{tabular}{|c|c|c|c|c|c|}
\hline $\begin{array}{l}\text { specimen } \\
\text { set }\end{array}$ & $\begin{array}{c}\text { number of } \\
\text { samples }\end{array}$ & aged & $\begin{array}{c}\mathrm{E}_{f} \\
{[\mathrm{MPa}]}\end{array}$ & $\begin{array}{c}\mathrm{F}_{\max } \\
{[\mathrm{N}]}\end{array}$ & $\begin{array}{c}\epsilon_{f} \\
{[\%]}\end{array}$ \\
\hline 1.1 & 2 & no & 16485 & 2150 & 2.79 \\
\hline 1.2 & 1 & yes & 7001 & 1705 & 2.39 \\
\hline 2.1 & 2 & no & 9427 & 1720 & 2.82 \\
\hline 2.2 & 3 & yes & 3636 & 1517 & 2.79 \\
\hline 3.1 & 2 & no & 7598 & 1655 & 3.05 \\
\hline 3.2 & 3 & yes & 3943 & 1470 & 2.77 \\
\hline
\end{tabular}

humiditiy. Among the different heating configurations the carbon fiber based heating device (see Figure 6 green lines) exhibits the comparatively highest mechanical properties which may be a result of a reinforcement of the EPDM by the fibers. Furthermore an effect by water absorption during the aging might be more critical for a continuous layer such as the CNT-paper than for a fiber fabric. Although the CNT-based heating devices are manufactured the same way there are big differences in their mechanical properties (see Figure 6 blue and purple lines). The only difference during manufacturing is the diameter-variation of the perforation which must be the explanation for the decreased properties. Actually the larger diameter is chosen to support a better cross-linking between EPDM and glass fiber and to avoid a separation as result of the CNT-paper. However, the found results reveal the opposite. Maybe the adhesion and composition of the interface between EPDM, gas-fiber prepreg and the intermediate CNT-paper is improved by a higher number of small holes per area instead of fewer but larger holes. Another advantage of the smaller holes can be seen using an infrared camera. Smaller holes reduce the appearance of hot spots which can be observed using the heating-paper with $10 \mathrm{~mm}$ holes.

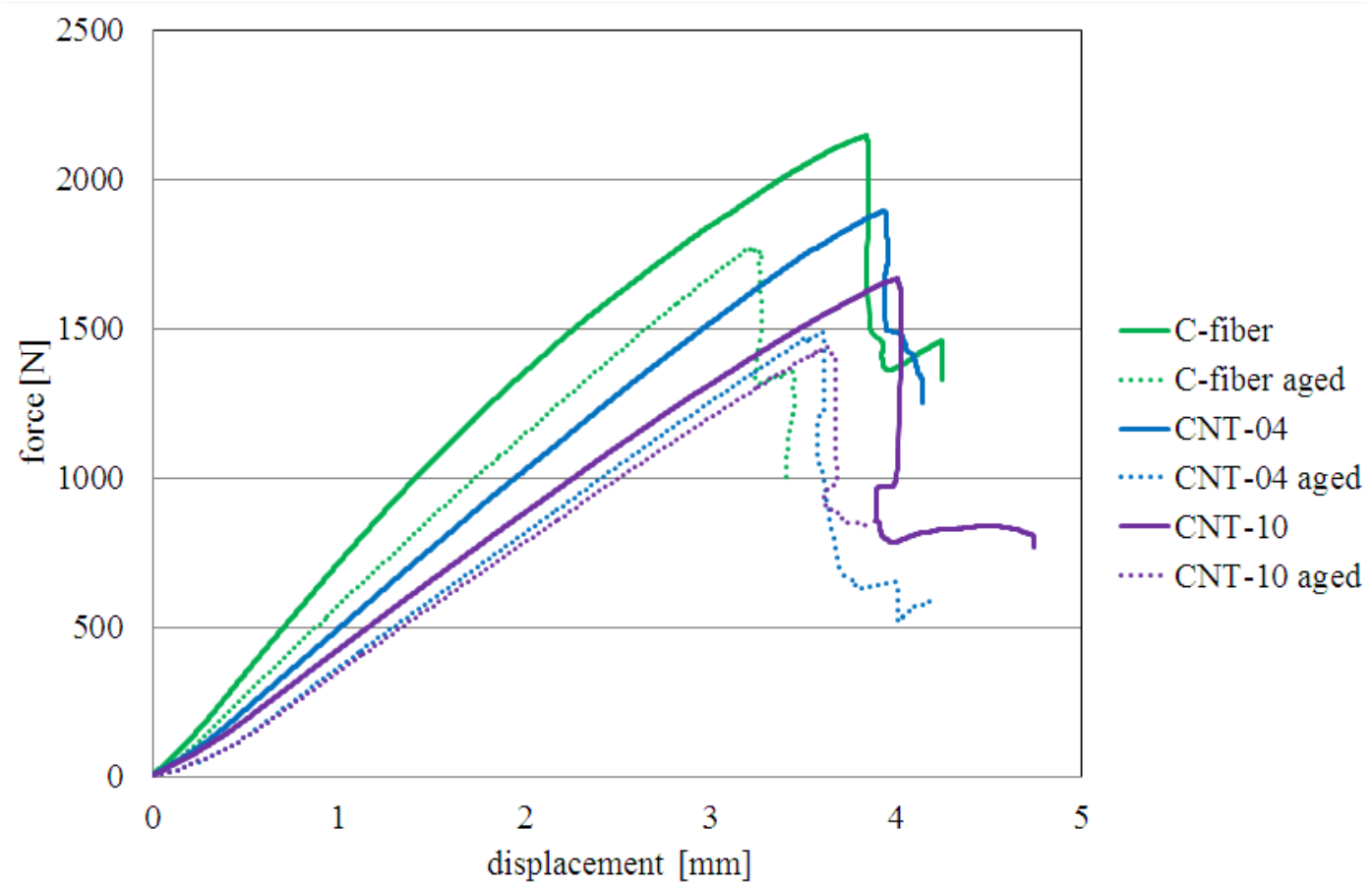

Figure 6. Force/deflection graphs of the different heating configurations featuring a comparison to the results of aged specimens.

The results of the strain gauges should support the approach to reduce the maximum strain of the outer layers by integrating EPDM which was simulated at first. In Figure 7 again four configurations are presented to emphasis the effect of elastomer integration. For better comparison the results of a specimen without an 
elastomeric layer is also shown as yellow line in Figure 7. As result of the test set-up the GFRP will be stressed by compression while the steel foil is tensile stressed. Interestingly the stress of the steel foil does not change significantly (apart from the CNT-D10 sample, purple dashed line in Figure 7). The carbon fiber based device (Figure 7 green lines) exhibits slightly higher strain-rates on both sides. So this configuration does not reduce the maximum strain at the outer layers. However, the strain is distributed equally on both sides so that the GFRP will not be plastically deformed by carrying the majority of the strain. The CNT-paper devices (blue and purple lines in Figure 7 exhibit reduced compression strain values at the upper GFRP-side which might be the result of the softer overall behavior which enables to decouple the stress. The high differences between the strain values on both sides may either be the result of a delamination between the layers along the CNT-paper or an adhesion failure of the strain gauges.

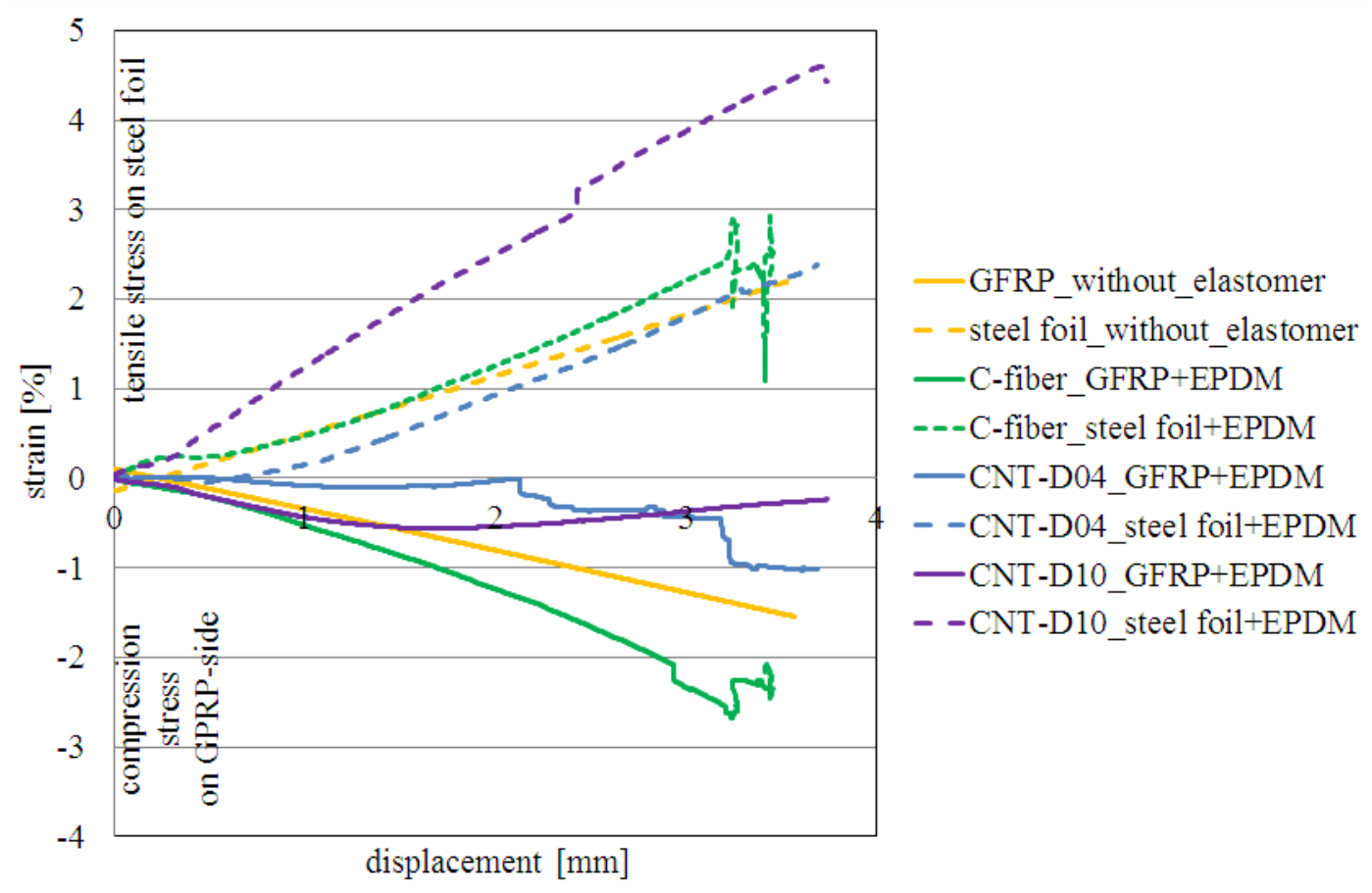

Figure 7. Strain/deflection graphs of the different heating configurations to emphasize the strain distribution on the side of the steel film (tensile stress) compared to the side of the GFRP (compression stress).

\subsubsection{Comparison of the experimental and simulated results at the droop nose demonstrator}

The application of an elastomeric layer positioned in the center between two GFRP laminates reveals a decreasing strain in the outer fibers of the whole laminate due to de-coupling of the two stiffer GFRP laminates. The larger the elastomeric layer the smaller the strains observed. Corresponding findings are made in the CLEANSKY 1 in which a full $300 \mathrm{~mm}$ droop nose section with such a layup was tested statically (see Figure 8 (M2-EPDM)). For monitoring the strain ten strain gauges (3/120 LY11, Hottinger Baldwin Messtechnik GmbH) were fixed on the circumference of the droop-nose demonstrator. However the integration of the elastomeric layer had no negative influence on the accuracy of the outer surface when actuated.

\section{CONCLUSIONS}

The presented paper expands the research of morphing skin materials in terms of combining material for multifunctional structures and simulative prediction of their mechanical behavior. As consequence of requirements two functions, erosion shielding and de-icing ability, are analyzed. The droop-nose concept of a varying thickness distribution is modified by these functions and has to be simulated for avoiding mechanical failure as result of high strain values at the outer layers. The simulation can clearly illustrate the shift of the bending line as 

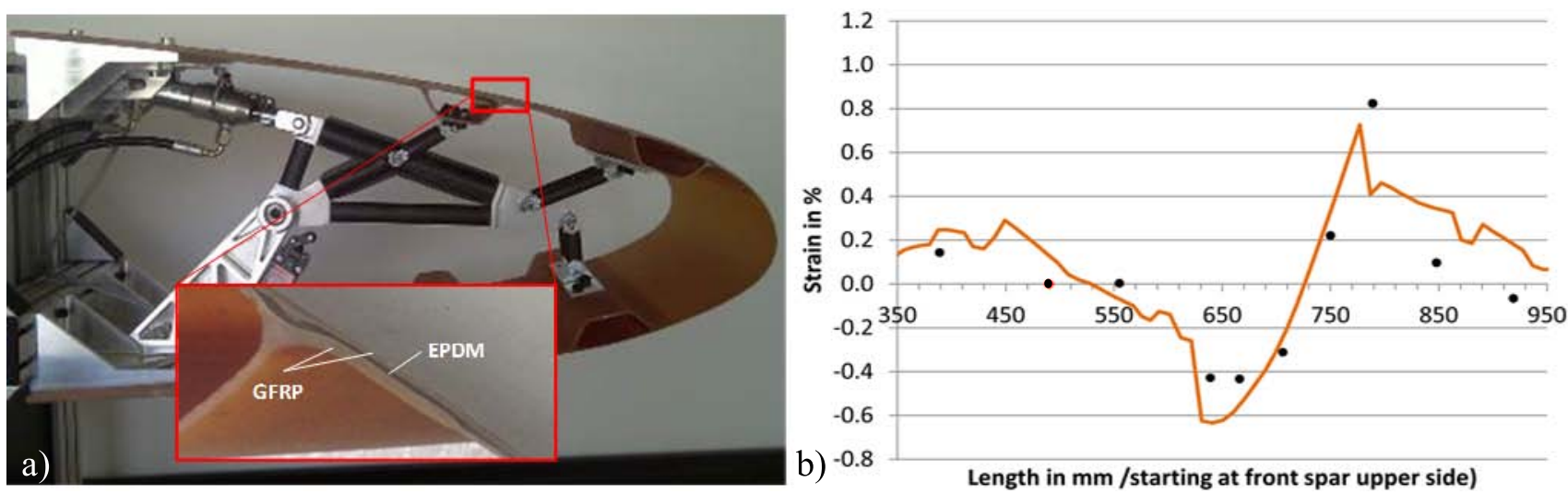

Figure 8. Overview of the demonstrator tests:

a) Tested demonstrator set-up.

b) Graphs of the tested (black points) and simulated (red, continuous line) maximum strains at the outer layers of the demonstrator circumference starting on the upper side at the front spar.

result of the stiff steel foil. As solution for this challenge the integration of an elastomeric layer is successfully simulated. From the numerical point of view it can be stated that the larger the elastomeric layer the lower the strain of the outer layers because of decoupling effects. On coupon-level these assumptions are tested at different integrated heating systems. Here elastomeric layers of the suggested size $(0.5 \mathrm{~mm})$ are integrated. On the one hand an aging effect of the device can be clearly demonstrated on the other hand the strain is distributed equally. But this effect can also be observed without an elastomeric layer. However, the CNT-paper devices reveal a comparatively higher reduction of the critical strain on the compression side. In a final droop-nose demonstrator the EPDM-integrated skin was tested revealing good agreement with the simulations. Maybe there are effects of the different test set-ups which can be simulated in different accuracy, the decoupling of morphing skins for function integration remains a challenging field.

Further steps have to be performed in terms of testing more samples for an adequate statistical basis. Moreover, samples of the same composition and geometry must be simulated and tested simultaneously for identifying set-up specific parameters which might not be transferred. At least an analytical calculation of the shift of the bending line has to be carried out in terms of easier prediction of the strain reduction as function of the elastomeric layer thickness.

\section{ACKNOWLEDGMENTS}

The presented work is carried out as part of the European programs SARISTU (integration stream IS12 and technology stream AS01) and JTI-SFWA Clean Sky program. Furthermore the work is based and strongly related on the results of the former project SADE (EU, FP7) in the DLR technology stream to develop a smart gap and step-less high-lift system at the leading-edge for commercial aircraft wings.

\section{REFERENCES}

[1] Campanile, F. L., Sachau, D., "The Belt-Rip Concept: A Structronic Approach to Varaiable Camber," Journal of Intelligent Material Systems and Structures 11, 215-224 (2000).

[2] Monner, H.-P., "Realization of an optimized camber by using formvariable flap structures," Aerospace Sience and Technology 5, 445-455 (November 2001).

[3] Thill, C., Etches, J. A., Bond, I. P., Potter, K. D. and Weaver, P. M., "Composite corrugated structures for morphing wing skin applications," Smart Materials and Structures 19(124009) (2010).

[4] Thill, C., Etches, J., Bond, I. P., Weaver, P. M. and Weaver, K. D., "Morphing Skins - A Review," The Aeronautical Journal 112(1129), 117-138 (2008).

[5] Sofla, A. Y. N., Meguid, S. A., Tan, K. T. and Yeo, W. K., "Shape morphing of airchraft wing: Status and challenges," Materials and Design 31, 1284-1292 (2010). 
[6] Barbarino, S., Bilgen, O., Rafic, A. M., Friswell, M. I. and Inman, D. J., "A Review of Morphing Aircraft," Journal of Intelligent Material Systems and Structures 22, 823-877 (2011).

[7] Baier, H., Datashvili, L., "Active and Morphing Aerospace Structures-A Synthesis between Advanced Materials, Structures and Mechanisms," International Journal of Aeronautical \& Space Science 12(3), 225-240 (2011).

[8] Vaista, S., Tong, L. and Wong, K. C., "Realization of Morphing Wings: A Multidisciplinary Challenge," Journal of Aircraft 49(1), 11-28 (2012).

[9] Santer, M., Pellegrino, S., "Topological Optimization of Compliant Adaptive Wing Structure," AIAA Journal 47(3), 523-534 (2009).

[10] Hetrick, J. A., Osborn, R. F., Kota, S., Flick, P. M. and Paul, D. B., "Flight testing of mission adaptive compliant wing," 48th AIAA/ASME/ASCE/AHS/ASC Structures, Structural Dynamics and Materials Conference (April 2007).

[11] Murray, G., Gandhi, F. and Bakis, C., "Flexible Matrix Composite Skins for One-dimensional Wing Morphing," Journal of Intelligent Material Systems and Structures 21(1771-1781) (2010).

[12] Peel, L. D., Mejia, J., Narvaez, B., Thompson, K. and Lingala, M., "Development of a simple Morphing wing using elastomeric composites as skins and actuators," Journal of Mechanical Design 131(9), 091003 (2009).

[13] Yokozeki, T., Takeda, S., Ogasawara, T. and Ishikawa, T., "Mechanical properties of corrugated compoistes for candidate materials of flexible wing structures," Composites Part A: applied science and manufacturing 37, 1578-1586 (2006).

[14] Kirn, T., Lorkowski, Baier, H., "Develoment of flexible matrix composites (FMC) for fluidic actuators in morphing systems," International Journal of Structural Integrity 2(4), 458-473 (2011).

[15] Rudenko, A., Monner, H.-P., Rose, M., "A Process Chain for Structural Optimization of a Smart Droop Nose for an Active Blown High Lift System," 22nd AIAA/ASME/AHS Adaptive Structures Conference, AIAA SciTech (1414) (2014).

[16] Datashvili, L., Baier, H., "Flexible fiber composites for space structures," In Cheng, Q., Fiber Reinforced Composites , 605-640 (2012).

[17] Zimmer, H., "Quertriebskörper mit veränderbarer Profilierung, insbesondere Flugzeugflügel," German Patent (No. DE 2907912-A1) (1979).

[18] Kintscher, M., Wiedemann, M., Monner, H.-P., Heintze, O. and Kühn, T., "Design of a smart leading edge device for low speed wind tunnel tests in the European project SADE," International Journal of Structural Integrity 2(4), 383-405 (2011).

[19] Wiedemann, J., "Leichtbau Elemente und Konstruktion," Springer-Verlag Berlin Heidelberg 3 (2007).

[20] Schürmann, H., "Konstruieren mit Faser-Kunststoff-Verbunden," Springer-Verlag Berlin Heidelberg 1 (2005).

[21] Heintze, O.,Geier, S., Hartung, D., Kintscher, M., Kling, A., Monner, H.-P. and Wierach, P., "Die Vorbereitung der Faserverbundstruktur einer flexiblen und spaltfreien Flügelvorderkante auf ihren ersten großskaligen Bodenversuch," German Aerospace Congress (DLRK) (2010).

[22] Leps, G., Ding, J., Steiner, R. and Lüderlitz, K., "Untersuchungen zum Erosionschutz kohlenstofffaserverstärker Duroplaste," Mat.-wiss., u. Werkstofftechnik 26, 374-378 (1995).

[23] Thomas, S., K., Cassoni, R., P., "Aircraft Anti-Icing and De-Icing Techniques and Modeling," Journal of Aircraft 33(5), 841-854 (1996).

[24] Strobl, T., Strom, S.,Thompson, D., Hornung, M., Thieleke, F., "Feasability Study of a Hybrid Ice Protection System," Journal of Aircraft 52(6), 2064-2076 (2015).

[25] Geier, S., Kintscher, M., Heintze, O., Wierach, P., Monner, H.-P. and Wiedemann, M., "Material characterization for morphing purposes in order to match flight requirements," Proc. SPIE 8341, Active and Passive Smart Structures and Integrated Systems 2012 834113 (2012).

[26] Geier, S., Kintscher, M., Heintze, O., Wierach, P., Monner, H.-P. and Wiedemann, M., "Characterization of multifunctional skin-material for morphing leading-edge applications," Proc. SPIE 8688, Active and Passive Smart Structures and Integrated Systems $2013 \mathbf{8 6 8 8 1 8}$ (2013).

[27] DIN EN ISO 14125, "Evaluation of bending properties," Berlin: DIN German Institute of Standards (1998). 